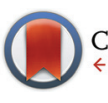

CrossMark \&lick for updates

Cite this: Dalton Trans., 2014, 43 17659

Received 29th May 2014

Accepted 7th August 2014

DOI: $10.1039 / c 4 d t 01399 a$

www.rsc.org/dalton

\title{
Modified bibenzimidazole ligands as spectator ligands in photoactive molecular functional Ru-polypyridine units? Implications from spectroscopy $\dagger$
}

\author{
Julia Meyer-Ilse, a,b Stefan Bauroth, ${ }^{a, b}$ Maximilian Bräutigam, ${ }^{\text {a,b }}$ Michael Schmitt, ${ }^{a}$ \\ Jürgen Popp, ${ }^{a, b}$ Rainer Beckert, ${ }^{c}$ Nils Rockstroh, ${ }^{d}$ T. David Pilz, ${ }^{d}$ Katharina Monczak, ${ }^{e}$ \\ Frank W. Heinemann, ${ }^{d}$ Sven Rau ${ }^{\mathrm{d}, \mathrm{e}}$ and Benjamin Dietzek ${ }^{\star a, b}$
}

\begin{abstract}
The photophysical properties of Ruthenium-bipyridine complexes bearing a bibenzimidazole ligand were investigated. The nitrogens on the bibenzimidazole-ligand were protected, by adding either a phenylene group or a 1,2-ethandiyl group, to remove the photophysical dependence of the complex on the protonation state of the bibenzimidazole ligand. This protection results in the bibenzimidazole ligand contributing to the MLCT transition, which is experimentally evidenced by (resonance) Raman scattering in concert with DFT calculations for a detailed mode assignment in the (resonance) Raman spectra.
\end{abstract}

\section{Introduction}

Bibenzimidazoles (bbims) have been proven to be versatile structures in the construction of environmentally sensitive photoactive Ru-complexes. ${ }^{1-6}$ One attractive aspect pointed out in the context of designing molecular photocatalysts and DNAintercalating luminescent complexes is the fact that bbims are non-electron accepting ligands. That is, when coordinated to, e.g., ruthenium ions together with, e.g., bipyridine, phenanthroline or related ligands, the bbim ligands do not partake in the metal-to-ligand charge transfer transition (MLCT). ${ }^{7-11}$ This feature renders bbim ligands interesting units in photoactive molecular devices, in which absorption of light initiates a vectorial electron transfer across the molecular structure. Here, the use of bbims as terminal ligands, i.e., ligands directed to

\footnotetext{
${ }^{a}$ Institute of Physical Chemistry and Jena Center for Soft Matter, Friedrich-Schiller University Jena, Helmholtzweg 4, 07743 Jena, Germany.

E-mail: benjamin.dietzek@uni-jena.de; Fax: +49 (0)3641 206399;

Tel: +49 (o)3641 206332

${ }^{b}$ Leibniz Institute of Photonic Technology (IPHT), Albert-Einstein-Straße 9,

o7745 Jena, Germany. E-mail: benjamin.dietzek@ipht-jena.de;

Fax: +49 (0)3641 206399; Tel: +49 (0)3641 206332

${ }^{c}$ Institute of Organic Chemistry and Macromolecular Chemistry, Humboldtstr. 8,

o7743 Jena, Germany

${ }^{d}$ Department of Chemistry and Pharmacy, Friedrich-Alexander University

Erlangen-Nuremberg, Egerlandstr. 3, 91058 Erlangen, Germany

${ }^{e}$ Institute of Inorganic Chemistry, University Ulm, Albert-Einstein-Allee 11,

89081 Ulm, Germany

$\dagger$ Electronic supplementary information (ESI) available: Experimental details and instrumentation, resonance Raman spectra recorded at excitation wavelengths of 458 and $488 \mathrm{~nm}$, emission data. See DOI: 10.1039/c4dt01399a
}

the opposite direction of the envisioned electron transfer acceptor, offers a promising option to enhance the directionality and efficiency of intramolecular electron transfer from the photoactive metal-unit to an acceptor unit. However, the noncoordinating nitrogen atoms of the bbim can be protonated/ deprotonated, which in turn changes the photophysical properties of the complexes, despite the fact that the latter are dominated by the non-bbim ligands. ${ }^{7}$ In this context, literature reports show that upon complete deprotonation of bbim-Rucomplexes, ${ }^{12}$ a loss of luminescence and a bathochromic shift of absorption maxima by up to $100 \mathrm{~nm}$ can occur. ${ }^{13}$ While this behaviour is essential for molecular sensors, e.g., molecular devices, whose photophysical properties are altered upon a change in the $\mathrm{pH}$-value of the solution, it is unwanted in molecular photocatalysts as, e.g., the $\mathrm{pH}$-value of a reaction solution can change quite drastically during the course of a catalytic reaction, which in turn would significantly impact the photoinduced molecular reaction steps determining the function of the catalyst itself. Therefore, bbim-structures have been designed in which the non-coordinating nitrogens are protected either by phenylene ${ }^{14}$ or an 1,2-ethandiyl group. To investigate the prospects of using these ligands as environmentally non-responsive spectator ligands in photoactive complexes, heteroleptic ruthenium complexes incorporating these new ligands and well-established tert-butyl-2,2'-bipyridine (tbbpy) ligands were synthesized and characterized spectroscopically. This study focuses specifically on complexes based on the (tbbpy $)_{2} \mathrm{Ru}\left(\mathrm{tmbbimH}_{2}\right)\left(\mathrm{PF}_{6}\right)_{2}\left(\mathbf{R u B i b}\right.$, tbbpy $=4,4^{\prime}$-ditert-butyl-2,2'-bipyridine, tmbbimH $_{2}=5,5^{\prime}, 6,6^{\prime}$-tetramethyl-2,2'bibenzimidazole). In particular, the work at hand focuses on 

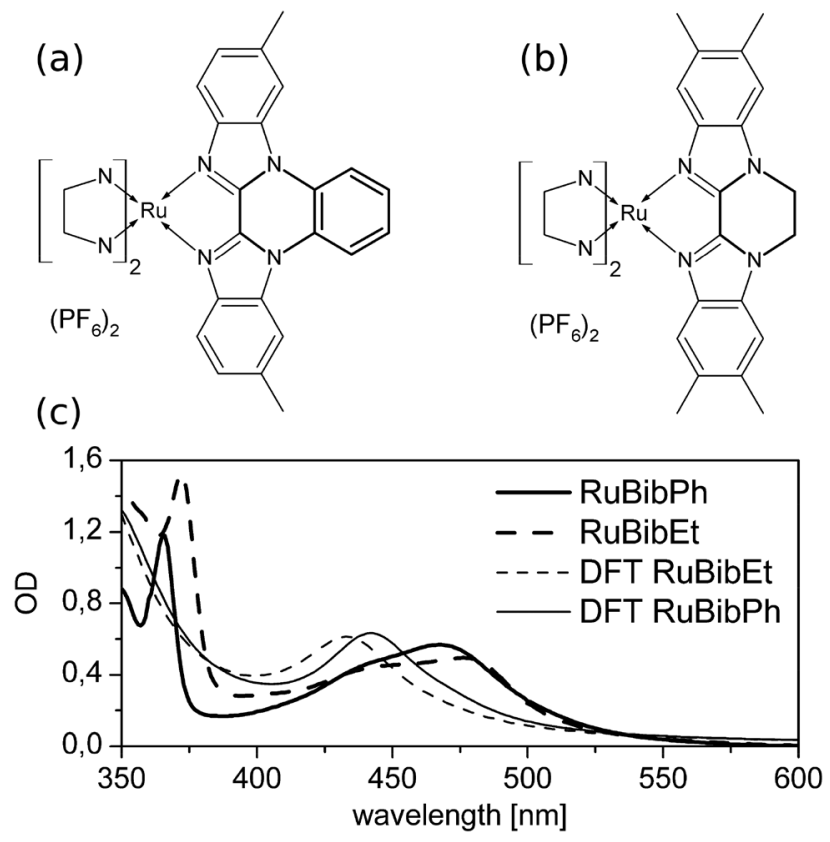

Fig. 1 Molecular structures of the two ruthenium complexes with protected bbim ligands where the NN ligand represents the tbbpy: (a) RuBibPh and (b) RuBibEt. (c) UV-Vis spectra of the two complexes measured in DCM and their calculated absorption spectra.

the spectroscopic characterization of [Ru(tbbpy $\left.)_{2}(\mathrm{dmbbimPh})\right]-$ $\left(\mathrm{PF}_{6}\right)_{2}(\mathbf{R u B i b P h})$, in which a phenylene group is attached to the bbim moiety, and $\left[\mathrm{Ru}(\mathrm{tbbpy})_{2}(\mathrm{tmbbimEt})\right]\left(\mathrm{PF}_{6}\right)_{2}$ (RuBibEt), in which an additional 1,2-ethandiyl group protects the imidazole nitrogens (see Fig. 1a and b, respectively). Thus, protection is accomplished by an aromatic group for RuBibPh and an aliphatic group in RuBibEt.

\section{Experimental}

\section{Synthesis and characterization}

Ruthenium trichloride and tert-butyl-pyridine were of reagent grade and used as supplied. $\mathrm{Ru}\left(4,4^{\prime}\right.$-di-tert-butyl-2,2'-bipyridine) ${ }_{2} \mathrm{Cl}_{2},{ }^{15} 4,4^{\prime}$-di-tert-butyl-2,2'-bipyridine, ${ }^{16,17}$ 1,1'-diphenylen6,6'-dimethyl-2,2'-bibenzimidazole, ${ }^{14} \quad 5,5^{\prime}, 6,6^{\prime}$-tetramethyl-2,2'bibenzimidazole ${ }^{18}$ and 1,1'-dimethylen-5,5',6,6'-tetramethyl-2,2'bibenzimidazole ${ }^{19}$ were prepared according to literature procedures.

The NMR spectra were recorded on a Bruker $400 \mathrm{MHz}$ spectrometer. The mass spectra were recorded with a SSQ 710 spectrometer (Finnigan MAT). Elemental analyses were performed on a Carlo Erba EA 1108. Steady state absorption spectra were obtained using a JASCO Spectrometer V-670. The CVs were recorded on a $\mu$ Autolab Type 3 Potentiostat/Galvanostat.\$ Intensity data for the compounds were collected on a Bruker Smart APEX2 diffractometer using graphite-monochro-

¥CV data for dinuclear bibenzimidazolate complexes show reversible redox chemistry also in the reductive part. Here a reversible reduction of all bipyridine ligands but no reduction of the bibenzimidazolate could be observed. ${ }^{33}$ mated $\mathrm{MoK}_{\alpha}$ radiation $(\lambda=0.71073 \AA)$. Data were corrected for Lorentz and polarization effects, and a semiempirical absorption correction based on multiple scans using SADABS $^{20}$ was applied $\left(T_{\min }=0.676, T_{\max }=0.746\right)$. Crystallographic data deposited at the Cambridge Crystallographic Data Centre under CCDC 1002151 for RuBibPh contain the supplementary crystallographic data excluding structure factors.

Bis(4,4'-di-tert-butyl-2,2'-bipyridine)(1,1'-diphenylen-6,6'dimethyl-2,2'-bibenzimidazole)-ruthenium(II)-dihexafluorophosphate (RuBibPh). In a $250 \mathrm{ml}$ round bottom flask, $20 \mathrm{mg}$ (0.059 mmol) 1,1'-diphenylen-6,6'-dimethyl-2,2'-bibenzimidazole and $42 \mathrm{mg}(0.059 \mathrm{mmol})$ bis(4,4'-di-tert-butyl-2,2'-bipyridin)-ruthenium(II)-dichloride were refluxed for $18 \mathrm{~h}$ in a mixture of $80 \mathrm{ml}$ ethanol and $20 \mathrm{ml}$ water. During the reaction, the colour changed from violet to orange. After cooling to room temperature the solvent was partially removed under reduced pressure and filtrated. To the reaction mixture an aqueous solution of $117 \mathrm{mg}(0.718 \mathrm{mmol})$ ammonium hexafluorophosphate was added. The resulting precipitate was filtrated and was washed with water and diethylether and dried in air. Yield: $46 \mathrm{mg}(61 \%)$.

${ }^{1} \mathrm{H}-\mathrm{NMR}\left(400 \mathrm{MHz}, \mathrm{CD}_{2} \mathrm{Cl}_{2}\right): \delta=8.61(\mathrm{~m}, 2 \mathrm{H}, \mathrm{H} 8$ " or $\mathrm{H} 9 ")$, $8.27\left(\mathrm{~d},{ }^{4} J(\mathrm{H} 3-\mathrm{H} 5)=2.0 \mathrm{~Hz}, 2 \mathrm{H}, \mathrm{H} 3\right.$ or $\left.\mathrm{H}^{\prime}\right), 8.23\left(\mathrm{~s}, 2 \mathrm{H}, \mathrm{H}^{\prime \prime}\right)$, $8.21\left(\mathrm{~d},{ }^{4} J\left(\mathrm{H}^{\prime}-\mathrm{H} 5^{\prime}\right)=1.8 \mathrm{~Hz}, 2 \mathrm{H}, \mathrm{H} 3^{\prime}\right.$ or $\left.\mathrm{H} 3\right), 8.01\left(\mathrm{~d},{ }^{3} \mathrm{~J}(\mathrm{H} 5-\right.$ $\mathrm{H} 6)=6.0 \mathrm{~Hz}, 2 \mathrm{H}, \mathrm{H} 6$ or $\left.\mathrm{H6}^{\prime}\right), 7.98\left(\mathrm{~d},{ }^{3} J\left(\mathrm{H}^{\prime}-\mathrm{H}^{\prime}\right)=6.2 \mathrm{~Hz}, 2 \mathrm{H}\right.$, H6' or H6), $7.88\left(\mathrm{~m}, 2 \mathrm{H}, \mathrm{H} 9^{\prime \prime}\right.$ or $\left.\mathrm{H} 8^{\prime \prime}\right), 7.53\left(\mathrm{dd},{ }^{3} J(\mathrm{H} 5-\mathrm{H} 6)=\right.$ $6.1 \mathrm{~Hz},{ }^{4} J(\mathrm{H} 3-\mathrm{H} 5)=2.1 \mathrm{~Hz}, 2 \mathrm{H}, \mathrm{H} 5$ or $\left.\mathrm{H} 5{ }^{\prime}\right), 7.35\left(\mathrm{dd},{ }^{3} J\left(\mathrm{H} 5^{\prime}-\right.\right.$ $\left.\mathrm{H} 6^{\prime}\right)=6.0 \mathrm{~Hz},{ }^{4} J\left(\mathrm{H} 3^{\prime}-\mathrm{H} 5^{\prime}\right)=2.0 \mathrm{~Hz}, 2 \mathrm{H}, \mathrm{H} 5^{\prime}$ or $\left.\mathrm{H} 5\right), 7.22(\mathrm{~d}$, $\left.{ }^{3} J\left(\mathrm{H} 4^{\prime \prime}-\mathrm{H} 5^{\prime \prime}\right)=8.6 \mathrm{~Hz}, 2 \mathrm{H}, \mathrm{H} 5^{\prime \prime}\right), 5.94\left(\mathrm{~d},{ }^{3} J\left(\mathrm{H} 4{ }^{\prime \prime}-\mathrm{H} 5^{\prime \prime}\right)=8.6 \mathrm{~Hz}\right.$, $2 \mathrm{H}, \mathrm{H} 4 "), 2.62\left(\mathrm{~s}, 6 \mathrm{H}, \mathrm{HMe}^{\prime \prime}\right), 1.49$ (s, 18H, HtBu or $\mathrm{HtBu}^{\prime}$ ), $1.35\left(\mathrm{~s}, 18 \mathrm{H}, \mathrm{HtBu}^{\prime}\right.$ or $\mathrm{HtBu}$ ) ppm (for assignment of the hydrogen atoms see ESI $\dagger$ ). ${ }^{13} \mathrm{C}-\mathrm{NMR}\left(100 \mathrm{MHz}, \mathrm{CD}_{2} \mathrm{Cl}_{2}\right): \delta=$ $162.7,162.3,159.6,157.2,153.1,152.3,141.0,139.8,138.3$, $132.5,128.9,128.2,127.1,125.8,124.4 ; 120.2,120.2$, 118.5, 116.5, 115.1, 35.6, 35.4, 30.2, 30.0, 22.0 ppm. MS Micro-ESI (MeCN/MeOH): $m / z=1119.3\left([\mathrm{M}-\mathrm{PF} 6]^{+}\right)$. EA: calculated for $4 \cdot \mathrm{C}_{58} \mathrm{H}_{64} \mathrm{~N}_{8} \mathrm{RuP}_{2} \mathrm{~F}_{12} \cdot \mathrm{HPF}_{6}$ : (C = 53.56\%, $\left.\mathrm{H}=4.98 \%, \mathrm{~N}=8.62 \%\right)$; found: $(\mathrm{C}=53.96 \%, \mathrm{H}=4.98 \%, \mathrm{~N}=8.39 \%)$. Photophysical data: Abs. $\lambda_{\max }(\mathrm{MeCN}): 465 \mathrm{~nm}, \lambda_{\max }(\mathrm{MeOH}): 465 \mathrm{~nm}, \lambda_{\max }$ $\left(\mathrm{CH}_{2} \mathrm{Cl}_{2}\right): 467 \mathrm{~nm}$. CV (MeCN, WE: glassy carbon, CE: Pt, RE: $\mathrm{Pt}$, internal standard: $\mathrm{Fc} / \mathrm{Fc}^{+}$, supporting electrolyte: $0.1 \mathrm{M}$ TBAPF $_{6}, 20 \mathrm{mV} \mathrm{s}^{-1}: 0.69 \mathrm{~V},-1.84 \mathrm{~V},-2.01 \mathrm{~V},-2.24 \mathrm{~V}$. Crystal data: $\mathrm{C}_{128} \mathrm{H}_{154} \mathrm{~F}_{24} \mathrm{~N}_{16} \mathrm{O}_{5} \mathrm{P}_{4} \mathrm{Ru}_{2}, M_{\mathrm{r}}=2778.69 \mathrm{~g} \mathrm{~mol}^{-1}$, size $0.18 \times$ $0.16 \times 0.08 \mathrm{~mm}^{3}$, monoclinic space group $P 2_{1}, a=15.632(3) \AA$, $b=22.082(4) \AA, c=19.317(4)(3) \AA, \alpha=90^{\circ}, \beta=96.899(3)^{\circ}, \gamma=$ $90^{\circ}, V=6620(2) \AA^{3}, T=150(2) \mathrm{K}, Z=2, \rho_{\text {calcd. }}=1.394 \mathrm{~g} \mathrm{~cm}^{-3}$, no. of reflections (measured): 104592 , no. of reflections (unique): 27331 , no. of parameters 1803/611, GooF $=1.081, R$ (reflection) $=0.0520$ (23 909), $\mathrm{w} R_{2}($ reflection $)=0.1238(27331)$, largest difference peak and hole: $0.71 /-0.61 \mathrm{e}^{-3}$.

Bis(4,4'-di-tert-butyl-2,2'-bipyridine)(1,1'-dimethylen-5,5',6,6'tetramethyl-2,2'-bibenzimidazole)-ruthenium(II)-dihexafluorophosphate (RuBibEt). In a $250 \mathrm{ml}$ round bottom flask, $64 \mathrm{mg}$ (0.202 mmol) 1,1'-dimethylen-5,5',6,6'-tetramethyl-2,2'-bibenzimidazole and $71 \mathrm{mg}(0.100 \mathrm{mmol})$ bis(4,4'-di-tert-butyl-2,2'bipyridin)-ruthenium(II)-dichloride were refluxed for $18 \mathrm{~h}$ in a 
mixture of $150 \mathrm{ml}$ ethanol and $37.5 \mathrm{ml}$ water. During the reaction the colour changed from violet to orange. After cooling to room temperature the solvent was partially removed under reduced pressure and filtrated. To the reaction mixture an aqueous solution of $150 \mathrm{mg}(0.902 \mathrm{mmol})$ ammonium hexafluorophosphate was added. The resulting precipitate was filtrated and was washed with water and diethylether and dried in air. Yield: $95 \mathrm{mg}(76 \%)$.

${ }^{1}$ H-NMR (400 MHz, $\left.0.5 \mathrm{ml} \mathrm{DMSO}+0.2 \mathrm{ml} \mathrm{CD} \mathrm{Cl}_{2}\right): \delta=8.82$ $\left(\mathrm{d},{ }^{4} J(\mathrm{H} 3-\mathrm{H} 5)=1.8 \mathrm{~Hz}, 2 \mathrm{H}, \mathrm{H} 3\right.$ or H3'), $8.75\left(\mathrm{~d},{ }^{4} J\left(\mathrm{H}^{\prime}-\mathrm{H}^{\prime}\right)=\right.$ $1.8 \mathrm{~Hz}, 2 \mathrm{H}, \mathrm{H}^{\prime}$ or $\left.\mathrm{H} 3\right), 8.03$ (d, ${ }^{3} J\left(\mathrm{H}^{\prime}-\mathrm{H} 6^{\prime}\right)=6.0 \mathrm{~Hz}, 2 \mathrm{H}, \mathrm{H}^{\prime}$ or H6), $7.90\left(\mathrm{~d},{ }^{3} J(\mathrm{H} 5-\mathrm{H} 6)=6.2 \mathrm{~Hz}, 2 \mathrm{H}, \mathrm{H} 6\right.$ or $\left.\mathrm{H6} 6^{\prime}\right), 7.67$ (s, $2 \mathrm{H}, \mathrm{H} 7 "), 7.63\left(\mathrm{dd},{ }^{3} J(\mathrm{H} 5-\mathrm{H} 6)=6.1 \mathrm{~Hz},{ }^{4} J(\mathrm{H} 3-\mathrm{H} 5)=2.1 \mathrm{~Hz}\right.$, $2 \mathrm{H}, \mathrm{H} 5$ or $\left.\mathrm{H}^{\prime}\right), 7.54\left(\mathrm{dd},{ }^{3} J\left(\mathrm{H}^{\prime}-\mathrm{H}^{\prime}\right)=6.2 \mathrm{~Hz},{ }^{4} J\left(\mathrm{H} 3^{\prime}-\mathrm{H} 5^{\prime}\right)=\right.$ $2.0 \mathrm{~Hz}, 2 \mathrm{H}, \mathrm{H} 5^{\prime}$ or $\mathrm{H} 5$ ), 5.50 (s, 2H, H4"), 4.98 (m, 4H, H8"), 2.33 (s, 6H, HMe6"), 2.06 (s, 6H, HMe5"), 1.47 (s, 18H, HtBu or $\mathrm{HtBu}^{\prime}$ ), 1.37 (s, 18H, HtBu' or $\mathrm{HtBu}$ ) ppm (for assignment of the hydrogen atoms see ESI $\dagger$ ). ${ }^{13} \mathbf{C}-\mathbf{N M R}(100 \mathrm{MHz}, 0.5 \mathrm{ml}$ $\left.\mathrm{DMSO}+0.2 \mathrm{ml} \mathrm{CD}_{2} \mathrm{Cl}_{2}\right): \delta=162.2,161.4,160.0,157.6,153.2$, $143.1,141.0,135.6,134.4,133.8,125.2$, 124.3, 121.7, 115.9, 113.6, 79.7, 43.8, 36.0, 35.9, 30.7, 30.6, 20.7, 20.6 ppm. MS Micro-ESI (MeCN/MeOH: $m / z=1099.3\left([\mathrm{M}-\mathrm{PF} 6]^{+}\right)$. EA: calculated for $\mathrm{C}_{56} \mathrm{H}_{68} \mathrm{~N}_{8} \mathrm{RuP}_{2} \mathrm{~F}_{12}:(C=54.06 \%, H=5.51 \%, N=$ 9.01\%); found: ( $C=53.82 \% ; H=5.51 \% ; N=8.86 \%$.). Photophysical data: Abs. $\lambda_{\max }(\mathrm{MeCN}): 469 \mathrm{~nm}, \lambda_{\max }(\mathrm{MeOH})$ : $463 \mathrm{~nm}, \lambda_{\max }\left(\mathrm{CH}_{2} \mathrm{Cl}_{2}\right): 477 \mathrm{~nm}$. CV (MeCN, WE: glassy carbon, CE: Pt, RE: Pt, internal standard: $\mathrm{Fc} / \mathrm{Fc}^{+}$, supporting electrolyte: $0.1 \mathrm{M} \mathrm{TBAPF}_{6}, 20 \mathrm{mV} \mathrm{s}^{-1}: 0.63 \mathrm{~V},-1.913 \mathrm{~V},-2.10 \mathrm{~V},-2.36 \mathrm{~V}$.

\section{Sample preparation}

For resonance Raman experiments the complexes were dissolved in DCM with an optical density of 0.5 at $475 \mathrm{~nm}$. To ensure sample integrity throughout the measurements, UV-Vis spectra (Jasco 530) were measured before and after each resonance Raman measurement.

\section{Resonance Raman scattering}

The details of the experimental set-up can be found elsewhere. ${ }^{7,21,22}$ In short, the excitation laser (Argon-Ion Laser 2018, Spectra-Physics) delivering the excitation light was focused into a rotating-cell cuvette. ${ }^{23}$ The scattered light was measured in $90^{\circ}$ geometry and focused onto the entrance slit of the spectrometer (Princeton Instruments/Acton SpectraPro 2750-0.750 Triple Grating Monochromator/Spectrograph). For the measurements a grating with 2400 lines per mm was used.

Measurements were performed at the excitation wavelengths of 458,476 , and $488 \mathrm{~nm}$. To compare the spectra a baseline was subtracted from the data and the spectra were subsequently normalized with respect to the solvent peak of dichloromethane at $1423 \mathrm{~cm}^{-1}$.

\section{Non-resonant Raman scattering}

The Raman measurements were performed on a Bruker FT-Raman spectrometer (Bruker MultiRAM). For this the Ru-complexes, in the solid-state, were inserted into the spectrometer and illuminated with the Nd:YAG laser at a wavelength of $1064 \mathrm{~nm}$.

\section{Quantum mechanical calculations}

Quantum mechanical calculations were performed with the GAUSSIAN09 ${ }^{24}$ program to obtain the structural and electronic data of the ruthenium complexes with protected bibenzimidazole ligands. For this, density functional theory (DFT) with the $\mathrm{XC}$ functional $\mathrm{B} 3 \mathrm{LYP}^{25,26}$ was used to calculate the geometry, vibrational frequencies and respective normal modes of the electronic ground state. The 28-electron relativistic effective core potential MWB2 $8^{27}$ was used with its basis set for the ruthenium atom; that is, $4 \mathrm{~s}, 4 \mathrm{p}, 4 \mathrm{~d}$ and $5 \mathrm{~s}$ electrons are treated explicitly, whereas the three first inner shells are described by the core pseudopotential. The $6-31 \mathrm{G}(\mathrm{d})$ double- $\zeta$ basis $\operatorname{set}^{28}$ was employed for the ligands. In order to unravel the nature of the excited states contributing to the absorption spectra, the first 120 singlet excited states have been calculated at the time-dependent DFT (TDDFT) level of theory using the same XC functional, pseudopotential and basis set. Effects of solvent interaction (dichloromethane) have been taken into account on the equilibrium geometries, vibrational frequencies, excitation energies, transition dipole moments and analytical Cartesian energy derivatives of the excited states by applying the integral equation formalism of the Polarizable Continuum Model (IEFPCM). ${ }^{29}$

Resonance Raman spectra were calculated using the sumover-states approach for the bright states in the range of excitation wavelength of $476 \mathrm{~nm}$, namely $\mathrm{S}_{3}, \mathrm{~S}_{4}, \mathrm{~S}_{6}$, and $\mathrm{S}_{7}$ (RuBibPh) as well as $\mathrm{S}_{3}, \mathrm{~S}_{5}, \mathrm{~S}_{6}$, and $\mathrm{S}_{7}$ (RuBibEt). ${ }^{12,30}$ In order to reproduce the experimental absorption in the region of the excitation wavelength, the excitation energies of the $S_{7}$ (RuBibPh) and the $\mathrm{S}_{6}$ (RuBibEt) states have been bathochromically shifted by $2000 \mathrm{~cm}^{-1}$ and the resulting absorption was broadened by Lorentzians with a FWHM of $3000 \mathrm{~cm}^{-1}$ (equivalent to a damping factor of $1500 \mathrm{~cm}^{-1}$ ). Detailed information concerning the computation of resonance Raman intensities can be found in the literature. ${ }^{12}$ To correct for the lack of anharmonicity and the approximate treatment of electron correlation, ${ }^{31}$ the harmonic frequencies were scaled by a factor of 0.97. To compare the calculated bands with the measured data, a Lorentzian function with a FWHM of $5 \mathrm{~cm}^{-1}$ was added to broaden the peaks.

\section{Results and discussion}

The synthesis of all ruthenium complexes was carried out according to known procedures. Structural characterization was performed with ${ }^{1} \mathrm{H},{ }^{13} \mathrm{C}$, ESI-mass spectrometry and elemental analysis. For RuBibPh it was possible to grow X-ray suitable crystals. The derived solid state structure from acetone-water is depicted in ESI Fig. $1 \uparrow$ together with relevant distances and angles (see ESI Table $1 \dagger$ ). The ruthenium centre is surrounded by nitrogen donor atoms in a distorted octahedral coordination geometry and, as for similar ruthenium 
complexes, ${ }^{32,33}$ the bond lengths $(2.034(4)-2.059(4) \AA)$ are shorter for the peripheral tbbpy as for the bibenzimidazole ligand (2.149(5) and (2.162(5) $\AA$ ). Noticeably the bond to the phenylene-bridged bibenzimidazole is longer than that for the bibenzimidazole in the parent compound RuBib (see ESI Table $1 \uparrow$ ). A possible explanation is the rigidity of the bibenzimidazole induced by the phenylene moiety whereby the ligand is not able to bend around the ruthenium centre. Mononuclear ruthenium bibenzimidazole complexes show a characteristic bending of the bibenzimidazole ligand around the ruthenium centre resulting in an angle of $167.1^{\circ} .^{32}$ In dinuclear complexes no bending is observed, i.e. an angle of $180^{\circ}$ can be measured. ${ }^{33}$ The same angle of $180^{\circ}$ is observed for RuBibPh.

The UV-Vis data of RuBibPh and RuBibEt dissolved in dichloromethane and the calculated absorption spectra are displayed in Fig. 1. The spectra of the two complexes show very similar structures: in the UV region a strong transition at about $370 \mathrm{~nm}$ is observed, which is assigned to a $\pi \pi^{*}$-transition. The characteristic MLCT bands are observed in the visible part of the spectrum between 400 and $550 \mathrm{~nm}$. The $\pi \pi^{*}$ and the MLCT-absorption maxima of RuBibEt are bathochromically shifted when compared to the absorption of RuBibPh by 441 and $405 \mathrm{~cm}^{-1}$, respectively.

In order to investigate the protection effect, the influence of the $\mathrm{pH}$-value on the UV-Vis transition was investigated. The absorption properties of both complexes are within experimental errors not significantly affected by increasing the solvent pH-value (see ESI Fig. $3 \dagger$ ), i.e. the sensitivity of the photophysical properties of the complexes to the $\mathrm{pH}$ value of the solution is drastically reduced when compared to the nonprotected parent complex RuBib. ${ }^{2}$

Investigations on the emission in DCM properties of both complexes show that for RuBibPh no emission can be observed and for RuBibEt some - albeit very weak - luminescence is visible at approximately $610 \mathrm{~nm}$.

In order to rationalise this finding, electrochemical studies were performed. The parent RuBib can be reversibly oxidised at $0.6 \mathrm{~V} v s$. $\mathrm{Fc} / \mathrm{Fc}^{+}$. However, due to irreversible electrochemical processes during the electrochemical measurements, no information is available for the reduction potentials of the coordinated ligands. For the complexes investigated here, the situation is changed: with respect to oxidation of the metal centre both complexes behave very similarly to the parent complex, i.e. the ruthenium centre is oxidized at potentials very similar to $\mathbf{R u B i b}$, i.e. at 0.69 and $0.63 \mathrm{~V}$ vs. $\mathrm{Fc} / \mathrm{Fc}^{+}$for RuBibPh and RuBibEt, respectively. However, three reversible

Table 1 Oxidation and reduction potentials of RuBibPh, RuBibEt, RuBib and $\left[\mathrm{Ru}(\text { tbbpy })_{3}\right]\left[\mathrm{PF}_{6}\right]_{2}$ in $\mathrm{MeCN}$

\begin{tabular}{lllll}
\hline Complex & $E_{\text {ox }}(\mathrm{V})$ & $E_{\text {red1 }}(\mathrm{V})$ & $E_{\text {red2 }}(\mathrm{V})$ & $E_{\text {red3 }}(\mathrm{V})$ \\
\hline RuBibPh & 0.69 & -1.84 & -2.01 & -2.24 \\
RuBibEt & 0.63 & -1.91 & -2.10 & -2.36 \\
RuBib & 0.60 & - & - & - \\
$\left.[\text { Ru(tbbpy })_{3}\right]\left[\mathbf{P F}_{6}\right]_{2}$ & 0.90 & -1.73 & -1.92 & -2.17
\end{tabular}

reduction processes can be observed at potentials comparable to the potentials observed for $\mathrm{Ru}(\mathrm{tbbpy})_{3}{ }^{2+}$ (see Table 1 and ESI Fig. $4 \dagger$ ). Interestingly for a structurally very similar complex, $\left[\mathrm{Ru}(\text { tbbpy })_{2}(\text { bibzim })\right]^{0} \quad$ (bibzim $=2,2^{\prime}$-bibenzimidazolate dianion), a fully reversible reduction under electrochemical conditions was observed. ${ }^{33}$ This observation supports the notion that the irreversibility of reduction processes in bibenzimidazole ruthenium complexes correlates with the presence of relatively acidic protons. Apparently the introduction of the protection groups changes the electrochemical behaviour significantly: The observed fully reversible behaviour could be explained by an accessible state localised on the modified Bibligand scaffold or by a multiple reduction process of the bound bipyridine ligands. In order to clarify this question, resonance Raman spectroscopy is employed to characterize the localization of the initial electronic transition. ${ }^{12,34-36}$

Resonance Raman spectra of both complexes were recorded upon excitation at 458, 476 and $488 \mathrm{~nm}$ and the resulting spectra were compared to those recorded for the homoleptic reference compound $\mathrm{Ru}(\mathrm{tbbpy})_{3}{ }^{2+}$ (Rutbbpy). The results are summarized in Fig. 2. In particular, Fig. 2(a-c) shows the

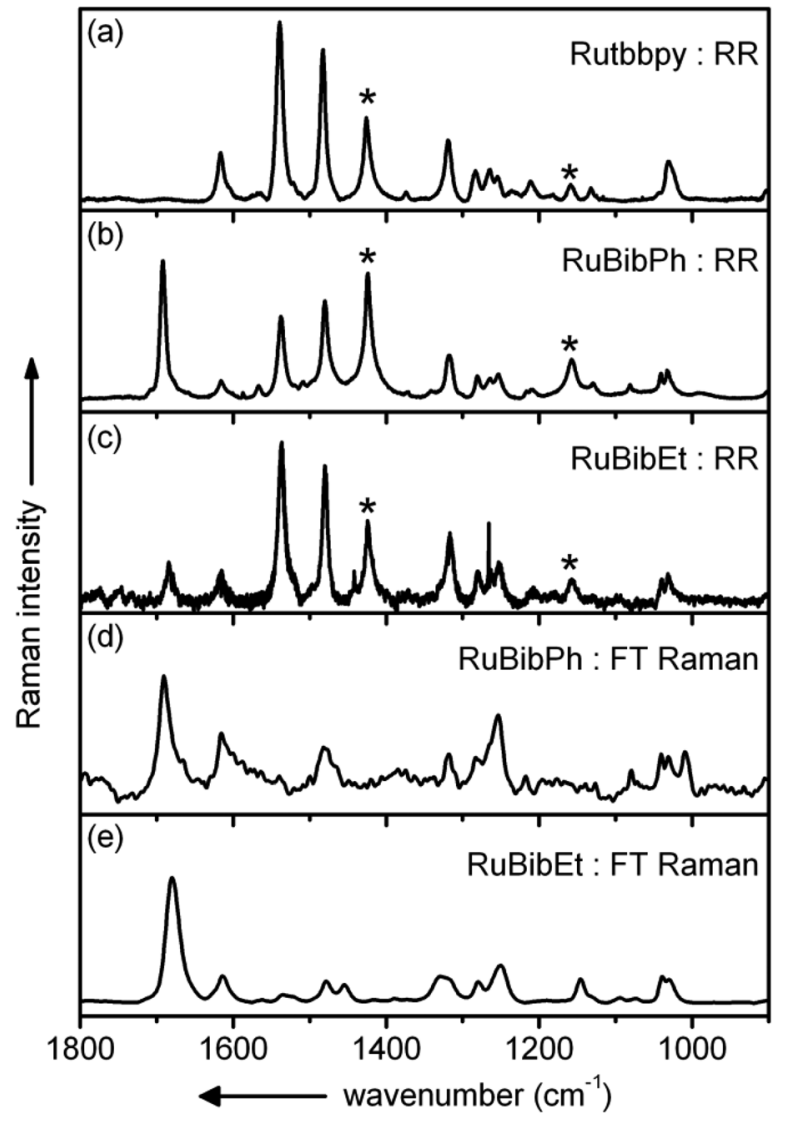

Fig. $2(\mathrm{a}-\mathrm{c})$ Experimental resonance Raman spectra of the protected bbim complexes in resonance with the absorption band in the visible range $\left(\lambda_{\mathrm{ex}}=476 \mathrm{~nm}\right)$. The experimental resonance Raman spectrum of the homoleptic reference complex Rutbbpy (a) is given for the assignment of the tbbpy vibrations. The DCM solvent bands are indicated by asterisks. (d, e) Experimental non-resonant Raman spectra of the protected bbim complexes ( $\lambda_{\mathrm{ex}}=1064 \mathrm{~nm}$ ). 
resonance Raman data recorded at $476 \mathrm{~nm}$ for all three complexes (see ESI Fig. 5 and $6 \dagger$ for resonance Raman spectra excited at different excitation wavelengths). For easier comparison all spectra are baseline corrected and normalized to the DCM peak at $1424 \mathrm{~cm}^{-1}$. Most bands in the resonance Raman spectra of the protected bbim ruthenium complexes can be associated with those of the reference complex Rutbbpy. For example, the symmetric ring-breathing modes of the tbbpyligand located at 1031 and $1040 \mathrm{~cm}^{-1}$ can be found in all three spectra. ${ }^{37}$ In the RuBibPh (RuBibEt) there exist bands at 1081 and $1692 \mathrm{~cm}^{-1}\left(1681 \mathrm{~cm}^{-1}\right)$ that are unique to the protected bbim complexes investigated here. They are found neither in the spectra of Rutbbpy nor in literature reports on related complexes bearing unprotected bbim ligands. .,11,37 $^{\text {To evaluate }}$ the molecular origin of these bands, non-resonant Raman measurements of RuBibPh and RuBibEt have been performed using solid powder samples of the complexes (Fig. 2d-e). These experiments are complemented by density functional theory (DFT) calculations (see Fig. 3) aimed at a detailed band assignment of the bands characteristic of the protected bbim structures. Based on the DFT calculations it can be shown that the band measured at $1081 \mathrm{~cm}^{-1}$ in RuBibPh is a ring breathing mode of the imidazole moieties on the protected bbimligand (see Fig. 4B). The weak band at $1499 \mathrm{~cm}^{-1}$ corresponds to ring stretching of the imidazole rings of the bbim ligand (see Fig. 4C) and the prominent band at $1692 \mathrm{~cm}^{-1}$ is a symmetric stretching mode located on the protected bbim-ligand

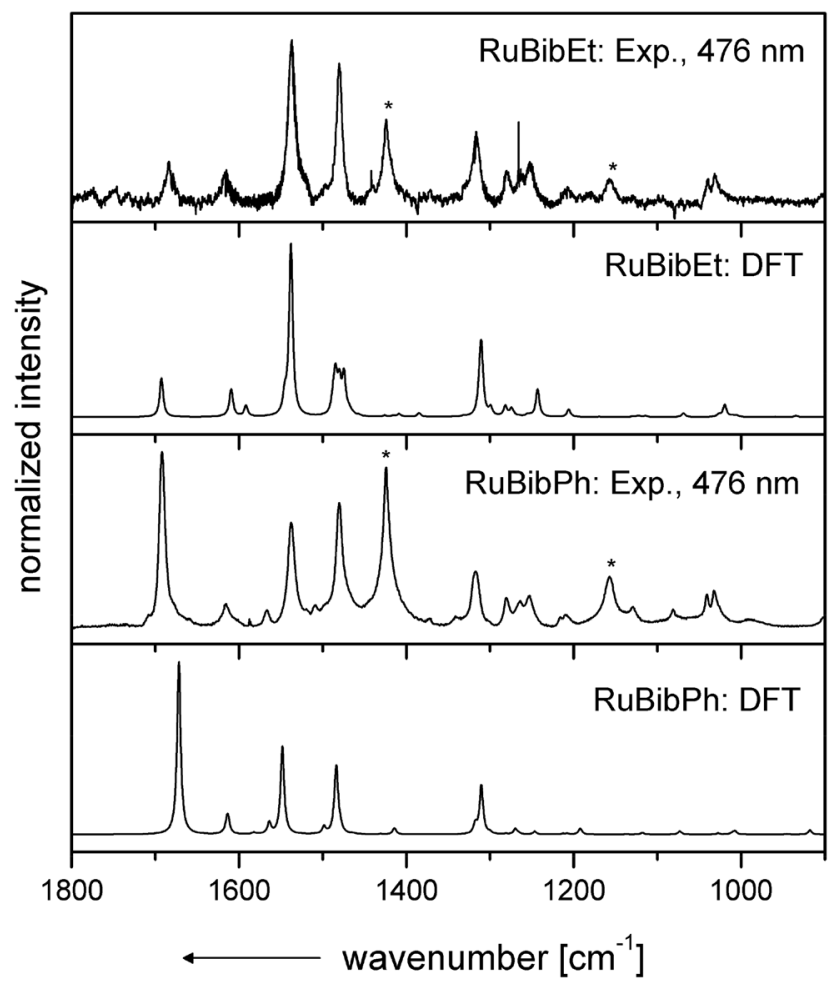

Fig. 3 Comparison of the experimental and calculated resonance Raman spectra of both RuBibPh and RuBibEt. The calculated spectra clearly evidence the contribution of the bbim ligands in the excited state (see bands at $>1670 \mathrm{~cm}^{-1}$ ).
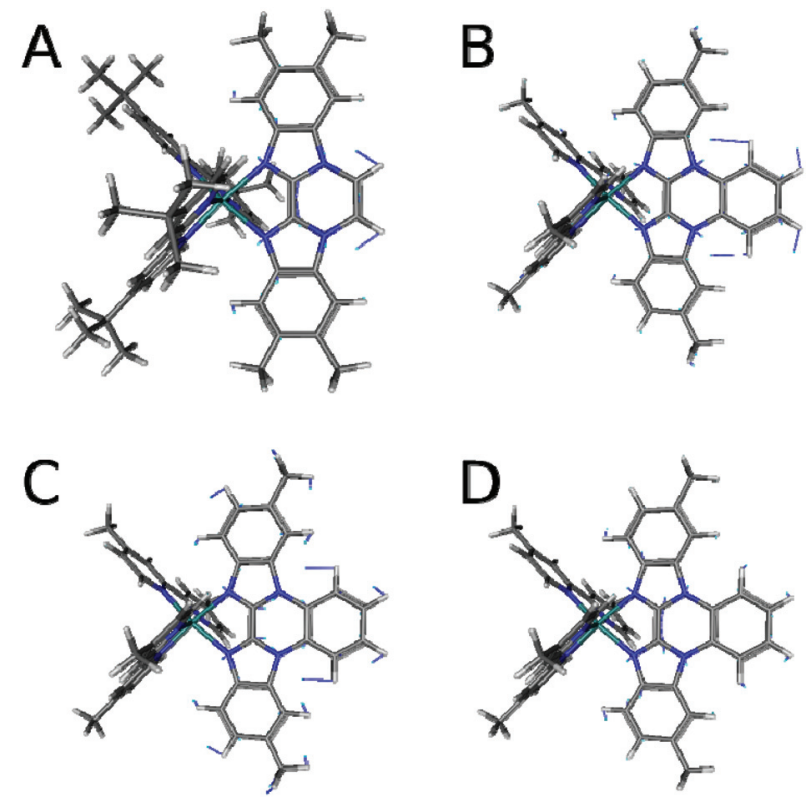

Fig. 4 Displacement vectors of the bbim vibrations from DFT calculations of the RuBib complexes. (A) RuBibEt at $1693 \mathrm{~cm}^{-1}$, (B) RuBibPh at 1073, (C) 1499, and (D) $1672 \mathrm{~cm}^{-1}$.

with maximal displacement along the $\mathrm{C}-\mathrm{C}$ bond between the imidazole moieties (see Fig. 4D). For RuBibEt the band at $1681 \mathrm{~cm}^{-1}$ is associated with a symmetric stretching mode of the bbim ligand with maximal displacement along the $\mathrm{C}-\mathrm{C}$ bond between the imidazole moieties and strong coupling to the stretching of the C-atoms of the 1,2-ethandiyl bridge connecting the two benzimidazoles (see Fig. 4A). A complete mode assignment is listed in Table 2.

These data reveal that - in contrast to unprotected bbim ligands - the protected ligands do participate in the MLCTtransition. Hence, the beneficial feature of the unprotected bbim ligands, i.e., acting as non-electron accepting spectator ligands on the photophysical properties of thus-derived $\mathrm{Ru}$ complexes, is lost.

The resonance Raman spectrum of RuBibEt reveals a reduced signal-to-noise ratio when compared to the spectrum of RuBibPh. This is due to the residual luminescence observed in the former case, which is entirely absent in the latter complex. The observation of a complete loss of luminescence for RuBibPh is potentially related to the extended $\pi$-electron scaffold in the protected Bib-ligand. The effect of an extended $\pi$-scaffold is thoroughly investigated and well understood for Ru-complexes bearing phenanthroline (phen) and dipyridophenazine (dppz) ligands. ${ }^{38,39}$ Here for instance, the phen-complexes show relatively strong emission in water with quantum yields in the range of $0.032-0.072,{ }^{40-42}$ while dppz complexes in water barely emit. Sophisticated insights into the dynamics in dppz complexes were achieved by using a combination of timeresolved resonance Raman, time-resolved infrared spectroscopy and DFT calculations. ${ }^{43}$ Thus, it is speculated that protection of the bbim-structure in RuBibPh creates an electronic situation comparable to the dppz ligand, which efficiently quenches the - 
Table 2 Comparison of the Raman-wavenumbers found for the two new complexes (RuBibPh and RuBibEt) using resonance Raman (456, 476, and $488 \mathrm{~nm}), \mathrm{FT}-$ Raman $(1064 \mathrm{~nm})$ and DFT-calculations. Also included are the resonance Raman data for the Rutbbpy complex, to identify the vibrations of the bibenzimidazole substructure (bbim)

\begin{tabular}{|c|c|c|c|c|c|c|c|c|c|c|c|}
\hline \multicolumn{5}{|c|}{ RuBibPh } & \multicolumn{5}{|l|}{ RuBibEt } & \multirow{2}{*}{$\begin{array}{l}\text { Rutbbpy } \\
\mathrm{cm}^{-1}\end{array}$} & \multirow[b]{2}{*}{ Description } \\
\hline $\begin{array}{l}\text { DFT } \\
\mathrm{cm}^{-1}\end{array}$ & $\begin{array}{l}456 \mathrm{~nm} \\
\mathrm{~cm}^{-1}\end{array}$ & $\begin{array}{l}476 \mathrm{~nm} \\
\mathrm{~cm}^{-1}\end{array}$ & $\begin{array}{l}488 \mathrm{~nm} \\
\mathrm{~cm}^{-1}\end{array}$ & $\begin{array}{l}1064 \mathrm{~nm} \\
\mathrm{~cm}^{-1}\end{array}$ & $\begin{array}{l}\mathrm{DFT} \\
\mathrm{cm}^{-1}\end{array}$ & $\begin{array}{l}458 \mathrm{~nm} \\
\mathrm{~cm}^{-1}\end{array}$ & $\begin{array}{l}476 \mathrm{~nm} \\
\mathrm{~cm}^{-1}\end{array}$ & $\begin{array}{l}488 \mathrm{~nm} \\
\mathrm{~cm}^{-1}\end{array}$ & $\begin{array}{l}1064 \mathrm{~nm} \\
\mathrm{~cm}^{-1}\end{array}$ & & \\
\hline \multirow[t]{2}{*}{1007} & 1031 & 1033 & 1032 & 1031 & \multirow[t]{2}{*}{1019} & \multirow[t]{2}{*}{1030} & 1032 & 1030 & 1030 & \multirow[t]{2}{*}{1030} & \multirow{2}{*}{ tbbpy, ring-breathing ${ }_{\text {sym }}$} \\
\hline & 1040 & 1041 & 1041 & 1041 & & & 1039 & 1039 & 1039 & & \\
\hline $1073^{a}$ & $1081^{a}$ & $1081^{a}$ & $1081^{a}$ & $1079^{a}$ & & & & & & & $\delta$-ring, bbim \\
\hline 1118 & 1129 & 1129 & 1130 & & & & & & 1146 & 1132 & $\delta$-CH, tbbpy \\
\hline 1208 & 1210 & 1210 & 1210 & 1217 & 1206 & 1206 & 1208 & 1206 & & 1212 & tbbpy, tert-butyl \\
\hline 1247 & 1254 & 1253 & 1253 & & 1243 & 1255 & 1253 & 1251 & 1250 & 1254 & $\nu$-CC tbbpy \\
\hline 1270 & 1280 & 1281 & 1281 & 1283 & 1274,1282 & 1278 & 1280 & 1280 & 1279 & 1283 & tbbpy, $\nu_{\text {asym-ring }}$ \\
\hline 1310 & 1317 & 1318 & 1320 & 1317 & 1310,1312 & 1315 & 1317 & 1315 & 1329 & 1319 & tbbpy, $\nu_{\text {asym-ring }}$ \\
\hline 1484 & 1480 & 1480 & 1481 & 1481 & 1485 & 1479 & 1480 & 1479 & 1478 & 1483 & tbbpy, $\nu_{\text {asym-ring }}$ \\
\hline $1499^{a}$ & $1509^{a}$ & $1509^{a}$ & $1509^{a}$ & & & & & & & & $\nu_{\text {sym}}$-ring, bibzimPh \\
\hline 1548 & 1538 & 1538 & 1537 & & 1538 & 1534 & 1537 & 1535 & 1535 & 1539 & tbbpy, $\delta$-ring, bbim \\
\hline 1564 & 1567 & 1566 & 1567 & 1540 & & & & & 1561 & 1566 & $\nu_{\text {sym,asym-ring tbbpy, bbim }}$ \\
\hline 1614 & 1616 & 1618 & 1616 & 1615 & 1609,1610 & 1615 & 1615 & 1613 & 1613 & 1617 & tbbpy, $\nu_{\text {asym }}$-ring \\
\hline $1672^{a}$ & $1692^{a}$ & $1692^{a}$ & $1692^{a}$ & $1691^{a}$ & $1693^{a}$ & $1681^{a}$ & $1684^{a}$ & $1682^{a}$ & $1680^{a}$ & & $\nu$-CC bbim \\
\hline
\end{tabular}

${ }^{a}$ Raman-active vibrational modes unique to the protected bibenzimidazole ligand.

anyhow weak - luminescence of RuBibEt. In analogy to dppz complexes this quenching is speculated to be achieved by ultrafast picosecond removal of electron density from the proximity of the coordinated Ru-ion to orbitals spatially separated ${ }^{38,43-51}$ a decay channel, which is apparently more prominently accessible in RuBibPh compared to RuBibEt.

\section{Conclusion}

The study presented here reveals that protecting the noncoordinating nitrogen atoms in bbim-ligands affects the photophysical properties of thereof derived Ru-complexes. It is shown that the protection route suggested here leads to a loss of the highly-advantageous feature of unprotected bbim ligands, i.e., the ability to act as non-electron accepting spectator ligands on Ru-polypyridine complexes. Furthermore, indications are reported that the protection of the non-coordinating nitrogens leads to dppz-like electronic structures in the ligand and resulting photophysical properties. The results presented suggest that the strategies pursued to date, to protect the uncoordinated nitrogen atoms of the bbim moiety against protonation/deprotonation and - at the same time - preserve the nature of the ligand as a non-electron accepting spectator ligand, do not succeed. One feasible alternative might be to use conventional Bib type ligands and form corresponding metal complexes with zinc centres as they render the compound $\mathrm{pH}$-value insensitive while at the same time retaining luminescence. ${ }^{7}$

\section{Acknowledgements}

Support by the COST Action CM1202 Perspect-H2O is highly acknowledged. The authors are thankful to Dr Maria Wächtler for fruitful discussions.

\section{Notes and references}

1 M.-A. Haga, Inorg. Chim. Acta, 1983, 75, 29-35.

2 A. M. Bond and M. Haga, Inorg. Chem., 1986, 25, 45074514.

3 M. Haga, T. Matsumura-Inoue and S. Yamabe, Inorg. Chem., 1987, 26, 4148-4154.

4 M.-A. Haga, Inorg. Chim. Acta, 1980, 45, L183-L184.

5 O. Takeshi, N. Koichi, I. Noriaki and H. Masa-aki, in Electron Transfer in Inorganic, Organic, and Biological Systems, American Chemical Society, 1991, vol. 228, pp. 215-228.

6 T. Ohno, K. Nozaki and M. Haga, Inorg. Chem., 1992, 31, 548-555.

7 M. Bräutigam, M. Wächtler, S. Rau, J. Popp and B. Dietzek, J. Phys. Chem. C, 2011, 116, 1274-1281.

8 B. Dietzek, W. Kiefer, J. Blumhoff, L. Böttcher, S. Rau, D. Walther, U. Uhlemann, M. Schmitt and J. Popp, Chem. Eur. J., 2006, 12, 5105-5115.

9 H.-J. Mo, Y.-L. Niu, M. Zhang, Z.-P. Qiao and B.-H. Ye, Dalton Trans., 2011, 40, 8218-8225.

10 D. P. Rillema, R. Sahai, P. Matthews, A. K. Edwards, R. J. Shaver and L. Morgan, Inorg. Chem., 1990, 29, 167175.

11 C. Herrmann, J. Neugebauer, M. Presselt, U. Uhlemann, M. Schmitt, S. Rau, J. Popp and M. Reiher, J. Phys. Chem. B, 2007, 111, 6078-6087.

12 M. Wächtler, J. Guthmuller, L. González and B. Dietzek, Coord. Chem. Rev., 2012, 256, 1479-1508.

13 S. Rau, T. Büttner, C. Temme, M. Ruben, H. Görls, D. Walther, M. Duati, S. Fanni and J. G. Vos, Inorg. Chem., 2000, 39, 1621-1624.

14 J. Preßler, R. Beckert, S. Rau, R. Menzel, E. Birckner, W. Günther and H. Görls, Z. Naturforsch., B: Chem. Sci., 2012, 67, 367-372. 
15 S. Rau, B. Schäfer, A. Grüßing, S. Schebesta, K. Lamm, J. Vieth, H. Görls, D. Walther, M. Rudolph, U. W. Grummt and E. Birkner, Inorg. Chim. Acta, 2004, 357, 4496-4503.

16 T. B. Hadda and H. Le Bozec, Polyhedron, 1988, 7, 575-577.

17 P. Belser and A. V. Zelewsky, Helv. Chim. Acta, 1980, 63, 1675-1702.

18 E. Muller, G. Bernardinelli and J. Reedijk, Inorg. Chem., 1995, 34, 5979-5988.

19 N. Schoenberger, E. Schinzel, T. Martini and G. Roesch, Bridged Quaternary Benzimidazolyl-Benzimidazole Derivatives, Process for Their Preparation and Their Use, EP0027897 (A1), May 6, 1981.

20 Bruker AXS Inc., SADABS 2008/1, Madison WI, U.S.A., 2008.

21 S. Tschierlei, B. Dietzek, M. Karnahl, S. Rau, F. M. MacDonnell, M. Schmitt and J. Popp, J. Raman Spectrosc., 2008, 39, 557-559.

22 M. Wächtler, S. Kupfer, J. Guthmuller, J. Popp, L. González and B. Dietzek, J. Phys. Chem. C, 2011, 115, 24004-24012.

23 W. Kiefer, Appl. Spectrosc., 1973, 27, 253-257.

24 M. J. Frisch, G. W. Trucks, H. B. Schlegel, G. E. Scuseria, M. A. Robb, J. R. Cheeseman, G. Scalmani, V. Barone, B. Mennucci, G. A. Petersson, H. Nakatsuji, M. Caricato, X. Li, H. P. Hratchian, A. F. Izmaylov, J. Bloino, G. Zheng, J. L. Sonnenberg, M. Hada, M. Ehara, K. Toyota, R. Fukuda, J. Hasegawa, M. Ishida, T. Nakajima, Y. Honda, O. Kitao, H. Nakai, T. Vreven, J. A. Montgomery Jr., J. E. Peralta, F. Ogliaro, M. Bearpark, J. J. Heyd, E. Brothers, K. N. Kudin, V. N. Staroverov, R. Kobayashi, J. Normand, K. Raghavachari, A. Rendell, J. C. Burant, S. S. Iyengar, J. Tomasi, M. Cossi, N. Rega, N. J. Millam, M. Klene, J. E. Knox, J. B. Cross, V. Bakken, C. Adamo, J. Jaramillo, R. Gomperts, R. E. Stratmann, O. Yazyev, A. J. Austin, R. Cammi, C. Pomelli, J. W. Ochterski, R. L. Martin, K. Morokuma, V. G. Zakrzewski, G. A. Voth, P. Salvador, J. J. Dannenberg, S. Dapprich, A. D. Daniels, O. Farkas, J. B. Foresman, J. V. Ortiz, J. Cioslowski and D. J. Fox, Gaussian 09, Revision A.1, Gaussian, Inc., Wallingford, CT, 2009.

25 A. D. Becke, J. Chem. Phys., 1993, 98, 5648-5652.

26 C. Lee, W. Yang and R. G. Parr, Phys. Rev. B: Condens. Matter, 1988, 37, 785-789.

27 D. Andrae, U. Häußermann, M. Dolg, H. Stoll and H. Preuß, Theor. Chim. Acta, 1990, 77, 123-141.

28 P. C. Hariharan and J. A. Pople, Theor. Chim. Acta, 1973, 28, 213-222.

29 J. Tomasi, B. Mennucci and R. Cammi, Chem. Rev., 2005, 105, 2999-3094.

30 S. Kupfer, M. Wächtler, J. Guthmuller, J. Popp, B. Dietzek and L. González, J. Phys. Chem. C, 2012, 116, 19968-19977.

31 J. P. Merrick, D. Moran and L. Radom, J. Phys. Chem. A, 2007, 111, 11683-11700.
32 N. Rockstroh, K. Peuntinger, H. Görls, D. M. Guldi, F. W. Heinemann, B. Schäfer and S. Rau, Z. Naturforsch., B: Chem. Sci., 2010, 65, 281-290.

33 S. Rau, M. Ruben, T. Büttner, C. Temme, S. Dautz, H. Görls, M. Rudolph, D. Walther, A. Brodkorb, M. Duati, C. O'Connor and J. G. Vos, J. Chem. Soc., Dalton Trans., 2000, 3649-3657.

34 W. R. Browne, P. Passaniti, M. T. Gandolfi, R. Ballardini, W. Henry, A. Guckian, N. O’Boyle, J. J. McGarvey and J. G. Vos, Inorg. Chim. Acta, 2007, 360, 1183-1190.

35 S. L. Howell, K. C. Gordon, M. R. Waterland, K. H. Leung and D. L. Phillips, J. Phys. Chem. A, 2006, 110, 1119411199.

36 N. J. Lundin, P. J. Walsh, S. L. Howell, J. J. McGarvey, A. G. Blackman and K. C. Gordon, Inorg. Chem., 2005, 44, 3551-3560.

37 M. Wächtler, M. Bräutigam, J. Popp and B. Dietzek, RSC Adv., 2013, 3, 5597-5606.

38 E. J. C. Olson, D. Hu, A. Hörmann, A. M. Jonkman, M. R. Arkin, E. D. A. Stemp, J. K. Barton and P. F. Barbara, J. Am. Chem. Soc., 1997, 119, 11458-11467.

39 M. K. Brennaman, T. J. Meyer and J. M. Papanikolas, J. Phys. Chem. A, 2004, 108, 9938-9944.

40 A. Juris, V. Balzani, F. Barigelletti, S. Campagna, P. Belser and A. von Zelewsky, Coord. Chem. Rev., 1988, 84, 85-277.

41 K. Nakamaru, Bull. Chem. Soc. Jpn., 1982, 55, 2697-2705.

42 A. Boisdenghien, C. Moucheron and A. Kirsch-De Mesmaeker, Inorg. Chem., 2005, 44, 7678-7685.

43 R. Horvath and K. C. Gordon, Inorg. Chim. Acta, 2011, 374, 10-18.

44 C. Kuhnt, M. Karnahl, S. Tschierlei, K. Griebenow, M. Schmitt, B. Schäfer, S. Krieck, H. Görls, S. Rau, B. Dietzek and J. Popp, Phys. Chem. Chem. Phys., 2010, 12, 1357-1368.

45 E. Amouyal, A. Homsi, J.-C. Chambron and J.-P. Sauvage, J. Chem. Soc., Dalton Trans., 1990, 1841-1845.

46 J. R. Schoonover, W. D. Bates and T. J. Meyer, Inorg. Chem., 1995, 34, 6421-6422.

47 G. Pourtois, D. Beljonne, C. Moucheron, S. Schumm, A. Kirsch-De Mesmaeker, R. Lazzaroni and J.-L. Brédas, J. Am. Chem. Soc., 2004, 126, 683-692.

48 Y. Sun, D. A. Lutterman and C. Turro, Inorg. Chem., 2008, 47, 6427-6434.

49 J. Fees, W. Kaim, M. Moscherosch, W. Matheis, J. Klima, M. Krejcik and S. Zalis, Inorg. Chem., 1993, 32, 166-174.

50 N. J. Lundin, P. J. Walsh, S. L. Howell, A. G. Blackman and K. C. Gordon, Chem. - Eur. J., 2008, 14, 11573-11583.

51 M. Atsumi, L. González and C. Daniel, J. Photochem. Photobiol., A, 2007, 190, 310-320. 